\title{
Reducing lead-times and lead-time variance in cooperative distribution networks
}

\author{
Author(s) \\ Ghaderi, Hadi; Dullaert, Wout; Ploos van Amstel, Walther \\ DOI
}

10.1504/IJSTL.2016.073316

\section{Publication date}

2016

Document Version

Final published version

\section{Published in}

International Journal of Shipping and Transport Logistics

\section{License \\ Unspecified}

Link to publication

\section{Citation for published version (APA):}

Ghaderi, H., Dullaert, W., \& Ploos van Amstel, W. (2016). Reducing lead-times and lead-time variance in cooperative distribution networks. International Journal of Shipping and Transport Logistics, 8(1), 51-65. https://doi.org/10.1504/IJSTL.2016.073316

If you believe that digital publication of certain material infringes any of your rights or (privacy) interests,

please let the Library know, stating your reasons. In case of a legitimate complaint, the Library will make the material inaccessible and/or remove it from the website. Please contact the library:

https://www.amsterdamuas.com/library/contact/questions, or send a letter to: University Library (Library of the University of Amsterdam and Amsterdam University of Applied Sciences), Secretariat, Singel 425, 1012 WP Amsterdam, The Netherlands. You will be contacted as soon as possible. 


\title{
Reducing lead-times and lead-time variance in cooperative distribution networks
}

\author{
Hadi Ghaderi* \\ Department of Maritime and Logistics Management, \\ National Centre for Ports and Shipping, \\ Australian Maritime College, \\ University of Tasmania, \\ TAS 7248, Australia \\ Email: Hadi.Ghaderi@utas.edu.au \\ *Corresponding author
}

\section{Wout Dullaert and Walther Ploos van Amstel}

Faculty of Economics and Business Administration, VU University Amsterdam,

De Boelelaan 1105, 1081 HV Amsterdam, The Netherlands

Email: w.e.h.dullaert@vu.nl

Email:w.ploosvanamstel@vu.nl

\begin{abstract}
The academic and professional attention to the large synergies hidden in horizontal collaborations is increasing. This study attempts to address the impact of collaborative transport on transportation lead-time and lead-time variability through empirically investigating a group of SMEs involved in a collaborative distribution network. Data was collected for seven pre-cooperation and eight cooperative orders over a period of 14 months. The results of Mann-Whitney U-test show a significant average reduction of $30.8 \%$ in the duration of lead times. Lead-time variability was also found to be reduced as the result of changes in the coefficient of variances and the Bartlett's test for homogeneity of variances. Horizontal collaboration in transport could eventually lead to reduced lead times and lower variability of lead time which results in reduced supply chain costs. This can be achieved by means of direct routing and avoiding multi-transshipment routes which reduces the uncertainty and variability by diminishing the number of stages in the transport chain. Thus, effective lead-time management is considered a source of competitive advantage as it can reduce supply chain costs by lowering inventory levels, but is also capable of improving performance and customer service by offering improved product quality service levels.
\end{abstract}

Keywords: lead time reduction; horizontal collaboration; reliability, logistics collaboration.

Reference to this paper should be made as follows: Ghaderi, H., Dullaert, W. and van Amstel, W.P. (2016) 'Reducing lead-times and lead-time variance in cooperative distribution networks', Int. J. Shipping and Transport Logistics, Vol. 8, No. 1, pp.51-65. 
Biographical notes: Hadi Ghaderi was involved as industrial consultant in the private sectors of food industry before continuing graduate studies. $\mathrm{He}$ graduated with Bachelor of Engineering in Industrial System Engineering from Shiraz Azad University, Iran and Master of Engineering in Engineering Management from University Putra Malaysia. He obtained his Masters in Transport and Maritime Economics from Institute of Transport and Maritime Management Antwerp (ITMMA), University of Antwerp. He is currently involved as a researcher, $\mathrm{PhD}$ student in rail logistics and casual lecturer at the Department of Maritime and Logistics Management, National Center for Ports and Shipping, Australian Maritime College. His research interest is in the areas lead time management and horizontal collaboration in transport and logistics, intermodal transport and rail logistics.

Wout Dullaert is Full Professor of Supply Chain Logistics at the VU University Amsterdam where he heads the logistics department. He is also affiliated with the Institute of Transport and Maritime Management Antwerp of the University of Antwerp. He currently lectures in supply chain, production, and operations management. His research and consulting activities focus on the (re)design of production and distribution systems, tactical and operational distribution problems, and cooperation strategies in logistics. He is the Vice Chairman of the Dutch-Flemish logistics network Vervoerslogistieke Werkdagen (http://www.vervoerslogistiekewerkdagen.org) and a member of the Board of the Benelux Association of Transport Economists (http://www.bivec-gibet.org). $\mathrm{He}$ is a member of the editorial board of European Journal of Industrial Engineering, Journal of Operations and Logistics and the Open Operational Research Journal.

Walther Ploos van Amstel is Associate Professor at Vrije Universiteit and Lecturer of City Logistics at Hogeschool van Amsterdam. His research is focused on sustainable logistics, urban distribution, development of main ports, sense and responds logistics, mobility and cross chain control centres. $\mathrm{He}$ received his Doctorate in Economics in 2002 from the Vrije Universiteit in Amsterdam for his research on logistics organisation. From 2002 to 2009, he was a Professor in Logistics at the Netherlands Defence Academy.

\section{Introduction}

According to Mason et al. (2007), management in the transport sector occurs along traditional lines rather than following the contemporary integrated approach. There is however, evidence supporting a move towards more partnerships and horizontal cooperation (Schmoltzi and Wallenburg, 2010). In fact, during the last two decades collaboration within the supply chain management has received a great deal of attention (Barratt, 2004). Horizontal partnerships have gained momentum among practitioners and academic researchers over the last five years. Logistics services, operating the physical link between different levels in supply chains, have a strong impact on the overall performance of a supply chain and provide numerous opportunities for collaboration. 
In particular, lead-time and inventory management play a crucial role in companies' overall supply chain efficiency and responsiveness. Effective lead-time management is considered a source of competitive advantage as it can reduce supply chain costs by lowering inventory levels, but also by improving performance and customer service by offering improved product quality service levels (Jayaram et al., 1999; Wedel and Lumsden, 1995; Fransoo and Wouters, 2000).

The focus of this paper is to empirically examine the impact of cooperative transport on the lead time and/or lead-time variability in a distribution network.

Despite existing research into the financial and strategic advantages of cooperation this study is - to the best of our knowledge - the first to examine evidence on lead time and lead-time variability in horizontal collaboration in transport. In addition, this study provides insights on the conditions for managing and/or reducing lead time in collaborative transport networks.

The remainder of this paper is as follows. Section 2 provides a focused literature review on collaboration trends in transport and logistics industry. The methodology to examine the impact of horizontal cooperation for a real-life case is described in Section 3. Section 4 provides the computational results and in Section 5 an extensive analysis with the managerial implications is presented. In the last section, conclusions are drawn and directions for further research are formulated.

\section{Literature review}

The development of complex and globally-operated supply chains in an increasingly competitive environment has encouraged logistics service providers (LSPs) to cooperate both vertically and horizontally (Mason et al., 2007). During the last decade, horizontal collaboration has been increasingly developed and is becoming a recognised organisational form in the logistics and transportation industry. According to Cruijssen (2006), horizontal collaboration is defined as active collaboration between two or more firms that operate on the same level of the supply chain and perform a comparable logistics function on the landside. A recent empirical study in Germany shows that almost $60 \%$ of LSPs engage in at least one horizontal partnership (Schmoltzi and Wallenburg, 2010). Horizontal collaboration is a well-known practice in maritime (Benacchio et al., 2007; Panayides and Wiedmer, 2011; Shepperd and Seidman, 2001) and aviation industries (Fan et al., 2001; Liou, 2012; Oum et al., 2002; Rhoades and Lush, 1997) in the form of alliances. Although the literature on horizontal collaboration for landside operations remains limited compared to the maritime and aviation industry, the body of research is growing steadily. This literature review focuses on horizontal collaboration in road haulage and landside operations, covering operational, tactical and strategic levels of cooperation.

As transport network planning and control can be considered to be the foundation of horizontal collaboration, it should be carefully defined and implemented. Several papers have explored operational planning in collaborative networks during the last decade. Cruijssen and Salomon (2004) perform a simulation study to estimate potential cost reductions by order sharing between transportation companies between 5 to $15 \%$. Cruijssen et al. (2007c) discussed the concept of joint route planning in horizontal collaboration amongst distribution companies. By applying joint route planning, 
economies of density can be attained and distribution costs can be lowered up to $30 \%$. The allocation of costs and profit sharing for cooperating freight carriers has been investigated by Krajewska et al. (2008) using the game theoretic solution concept of the Shapley value. Frisk et al. (2010) examined a case study on transportation of forest products in Sweden. The authors proposed a cost and saving distribution model based on equal profit method (EPM). In this model, the potential cost savings depend on the geographical distribution of the companies in the coalition. Hence, as companies become aware of the strategic importance of their geographical location, some request a larger share of the cost savings.

Ghaderi et al. (2012) examine the transportation cost savings of horizontal collaboration on transport services within purchasing groups. The outcome of their empirical study shows a reduction of 10 to $30 \%$ in outbound logistics cost or tariffs in comparison to the time period in which the firms were organising procurement by themselves.

Also from a tactical point of view, horizontal collaboration has received growing academic research interest. Regarding allocation of costs in collaborative transportation networks, Ozener and Ergun (2008) developed a model to ensure the sustainability of collaboration based on cooperative game theory.

Fourth-party logistics management (4PL) was proposed to coordinate horizontal collaboration between retailers (Hingley et al., 2011). Involvement of LSPs in 4PL management requires significant investment in IT. This is considered a barrier but simultaneously offers potential benefits to cooperation. Results from same study shows major LSPs appear reluctant to get involved in 4PL businesses.

Depending on the possible or desired cooperation level, various characteristic forms of cooperation were investigated by Leitner et al. (2011), ranging from the joint offering of transport and logistics services to the coordination of logistics and production planning. More intense cooperation was shown to lead to higher potentiality in consolidation, monetary savings and efficiency. The authors consider a neutral coordination as the guarantee for sustainable success in cooperation between LSPs. Audy et al. (2011) report on a real-life case of four furniture manufacturers involved in collaborative transportation. They design a cost allocation structure and perform a sensitivity analysis to ensure a minimum amount of savings to convince manufacturers to join the collaboration.

Strategic levels of horizontal collaboration in transportation have also gained momentum in the last years. Wallenburg and Raue (2011) investigated the role of governance mechanisms on the conflicts in horizontal collaboration between LSPs. They showed that relational governance lowers the extent of conflicts in cooperation, while formal governance leads to a higher conflict level. Furthermore, conflicts decrease the overall performance of cooperation. Cruijssen et al. (2007a) proposed the first large-scale empirical study on the potential benefits of horizontal collaboration in logistics and transportation as well as discussing the main impediments to establishing and maintaining partnerships in practice. Participants in the survey consider horizontal collaboration as a motivating option to improve their customer service, but the main motive was reducing operational costs.

In the first literature review on horizontal collaboration in transport and logistics, Cruijssen et al. (2007b) identified a lack of a conceptual classification for horizontal collaboration between LSPs as well as structures for managing and operating cooperation to be of key importance. 
Mason et al. (2007) describe the competitive advantage that transportation companies can achieve through combining the collaboration of vertical supply chain partners with the horizontal approach. Combining both vertical and horizontal collaboration provides innovative solutions for better transport optimisation as well as logistical performance. Verstrepen et al. (2009) identified the major motives and drivers for LSPs to establish horizontal collaboration. Secondly, a classification of supporting structure for LSPs searching for cooperation was proposed. Thirdly, the typical life cycle of partnership and the management over the time was described. Regarding the typology of horizontal collaboration among LSPs, Schmoltzi and Wallenburg (2010) define six distinctive types of cooperation. An additional insight of this study was to show horizontal collaboration between LSPs is substantially more stable than other partnerships reported by other scholars (Park and Ungson, 2001; Kale et al., 2002; Hoang and Rothaermel, 2005).

Yilmaz and Savasaneril (2012) studied the coalition formation among small shippers in a transportation market under uncertainty conditions. The analysis shows that the shippers always benefit from coalition, but when the benefits are to be allocated, the coalition may not always guarantee the budget balance, which is fundamental for sustainability of any coalition.

Over the last few years, the practical relevance and academic challenges have increased the available literature on horizontal collaboration logistic, especially on the allocation of costs and on sharing gains In this literature review, we discussed the available research on horizontal collaboration in transport and logistics by first focusing on operation, tactical and strategic levels. A large proportion of available literature is associated with the operational and strategic streams. Within the operational level, research lies with an empirical-based approach, while the strategic level of cooperation has been discussed on a theoretical basis. If we are to argue that horizontal collaboration in transport and logistics offers various opportunities based on the evidences from the empirical operational cases, and the studies from the strategic level offer a different range of theoretical solutions, it remains a concern that there is insufficient work on the tactical aspects to deliver the strategic directions to the operational decision making of cooperation.

In addition, the focus of the available literature on the potential synergies of collaboration has been mainly on the direct monetary benefits such as transportation costs savings. Although reducing the lead-time and lead-time variance could result in lowered inventory levels and associated costs, in this study we examine this phenomenon from a time-management perspective and not the supply chain finance viewpoint.

\section{Methodology and case study description}

The important role of lead-time reduction in supply chain and inventory management has been widely recognised by practitioners and academic researchers (Leng and Parlar, 2009). Recognising the importance of lead-time management, several papers have been published, ranging from pure mathematical to qualitative approaches. Although this amount of research is solid evidence of the importance of control over the lead times, important research challenges still remain.

To gain control over the lead time, the first step is to identify its constituent components (Tersine and Hummingbird, 1995). According to Leng and Parlar (2009), total lead time faced by a retailer from manufacturer consists of three independent 
components: setup time $\left(L_{1}\right)$, production time $\left(L_{2}\right)$, and transportation time $\left(L_{3}\right)$; accordingly,

$$
\text { Total lead time }=L_{1}+L_{2}+L_{3}
$$

For the purpose of this research, we specifically focus on $L_{3}$ which is associated with transportation time. Cruijssen (2006) states horizontal collaboration is often the fastest way to reduce response times, obtain first mover advantages or successfully enter a new market. This has been confirmed by practical evidence of cooperating LSPs in Western Europe (Krajewska et al., 2008; Schmoltzi and Wallenburg, 2010). However, the focus of previous works is more on the response time than the shipping time in the cooperation. An example of reduced lead-times made possible by a cooperative logistics concept, is when carrier companies exchange orders to cut lead times down to levels that would be impossible to achieve individually (Cruijssen, 2006).

By merging (a part of) the distribution processes of the partnering companies (often referred to as joint route planning or truck sharing), important efficiency savings can be obtained for shippers and LSPs involved (Cruijssen et al., 2007a).

In 2010, five small and medium-sized confectionary firms located in Southern Iran decided to consolidate their shipments from their mutual suppliers in order to minimise their transportation costs. The targeted materials were not strategic in the nature and were not subject to seasonal differences in supply. Following Hendrick (1997), this facilitates cooperation as strategic materials would raise the threats of exchanging strategic information which can affect the partnership.

Before establishing the cooperation, due to unavailability of direct shipping routes, the shipments to the confectionary firms were delivered individually from suppliers in the south, northwest and northeast of the country through two or three consolidation centres. In the new situation, the shipments are consolidated at the supplier's plant and are transported by full truckload (FTL). As such, the cooperation allowed the confectionary firms to eliminate the need for consolidation during the route at a consolidation centre. The responsibility of placing, receiving the orders and organising the transportation service was delegated to a purchasing consortium acting as a third party coordinator. In this case, we can consider the purchasing consortium to be acting as a 4PL transport orchestrator. Cooperation in transport of purchased goods by consortia can support reduced lead-times and higher delivery frequencies or lower the fixed cost of placing/receiving and order (Ghaderi and Dullaert, 2012).

In this paper, we compare the lead time and lead-time variability during the cooperative transportation with traditional distribution and address the conditions in which lead-time reduction can be obtained in a cooperative less-than-truckload (LTL) transportation network. Because the transportation time accounts for a very large proportion of the total lead time in this particular case, the handling and logistical times at grouping/de-grouping points are excluded from the calculations. In addition to the average lead time, we also want to examine the impact of cooperation on the variability of lead times. Reducing the variability of lead time results in lower inventory cost by reduced the safety stock (Simchi-Levi et al., 1999). The collaboration case consists of three coalitions for firms in which each coalition is associated with one supplier. The geographical distances and schematic view of suppliers and participating firms are presented in Table 1 and Figure 1. 
Reducing lead-times and lead-time variance

Table 1 Distances between players in cooperation $(\mathrm{km})$

\begin{tabular}{ccccccccc}
\hline & Firm1 & Firm2 & Firm3 & Firm4 & Firm5 & Supplier1 & Supplier2 & Supplier3 \\
\hline Firm1 & - & - & - & - & - & 1,628 & 1,297 & 797 \\
Firm2 & 10 & - & - & - & - & 1,644 & 1,307 & 802 \\
Firm3 & 53 & 67 & - & - & - & - & 1,242 & - \\
Firm4 & 19 & 16.5 & 71 & - & - & 1,659 & - & 791 \\
Firm5 & 20 & 17.5 & 72 & 1 & - & 1,660 & - & 792 \\
\hline
\end{tabular}

Figure 1 Geographical locations of suppliers and firms in region (see online version for colours)
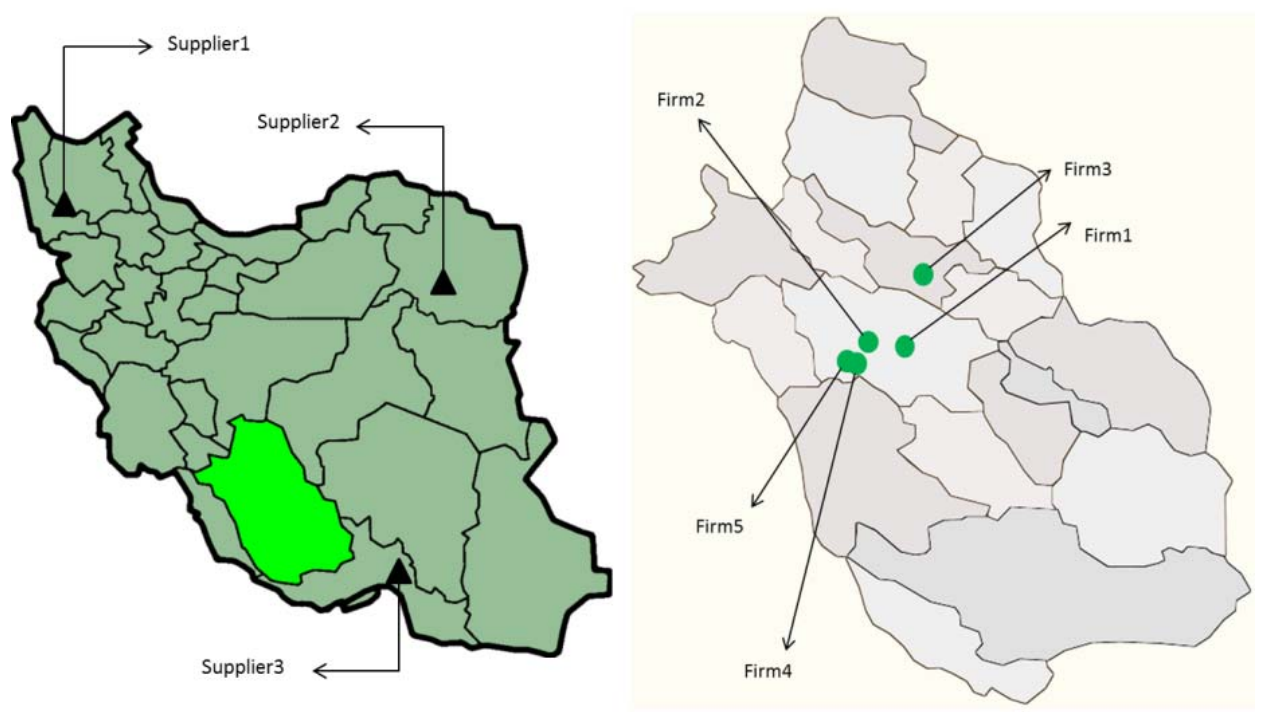

Figure 2 Coalitions and joint route networks
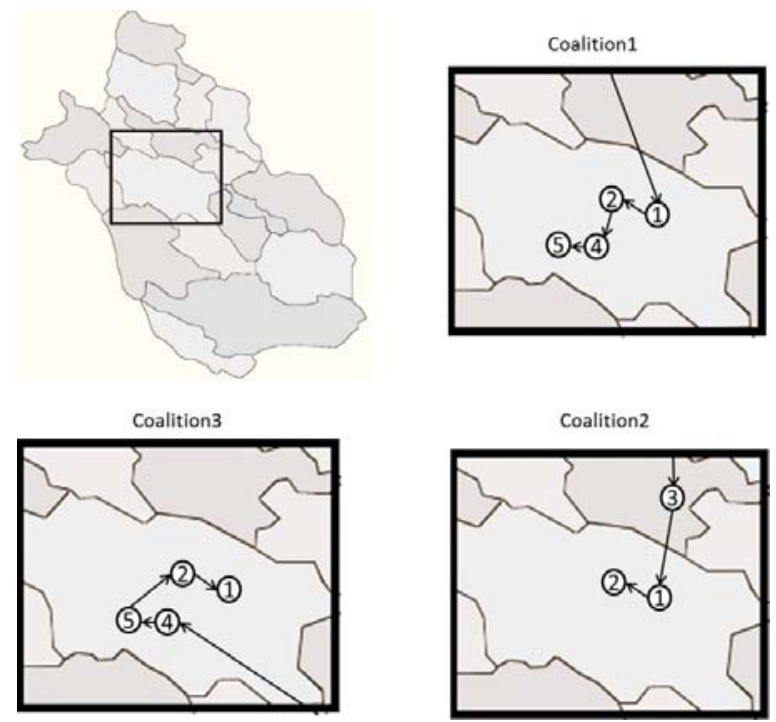
Based on the geographical position of the firms in the coalition, the closest firm to the supplier receives the first shipment. However, from the collected data, it was observed that there are exceptions in the order of the deliveries (e.g. in one order of Coalition1, Firm2 was visited before Firm1). Figure 2 demonstrates the distribution network between the firms.

While most of the previous studies on horizontal collaboration in transport and logistics focus on LSPs, this paper considers shippers managing the transport of consignments from their mutual suppliers. Quantitative surveys were designed, tested and the responsible departments were contacted through phone, e-mail and direct interviews. The surveys focused on quantitative records of transportation lead time, arrival times for both pre-cooperation and cooperative periods. Data collection period consisted of six months of pre-cooperation and eight months of cooperative transport, consisting of seven and eight orders respectively from categorised files stored in both companies and purchasing consortium. There are some orders procured individually and the lead times collected here only consist of orders in which all the coalition members are involved.

To examine the impact of horizontal collaboration on transport lead times, the average lead times for before and after cooperation periods was compared by using of the non-parametric Mann-Whitney U-test under a significance level of 5\%:

$$
\begin{aligned}
& H_{0}: \mu_{L T B C}=\mu_{L T A C} \\
& H_{1}: \mu_{L T B C}>\mu_{L T A C}
\end{aligned}
$$

Lead-time variability plays a crucial role in the safety stock and procurement planning of industrial firms. To examine the difference between the variances of lead times, we will use the coefficient of variation (CV) which allows us to compare the relative changes in variance of lead times for both time periods.

\section{Analysis and findings}

The first and the main objective of this research focuses on the change in the lead times experienced by the shippers participating in a horizontal collaboration. Table 2 presents a summary of lead times for pre-cooperation and cooperative times. For both periods, the minimum, maximum, mean duration and standard deviation (SD) of the lead times are reported.

\begin{tabular}{|c|c|c|c|c|c|c|c|c|c|}
\hline \multirow{2}{*}{ Coalition } & \multirow{2}{*}{ Firm } & \multicolumn{3}{|c|}{ Before collaboration } & \multirow{2}{*}{$S D$} & \multicolumn{3}{|c|}{ After collaboration } & \multirow{2}{*}{$S D$} \\
\hline & & Min & $\operatorname{Max}$ & Mean & & Min & $\operatorname{Max}$ & Mean & \\
\hline \multirow[t]{4}{*}{1} & 1 & 51 & 99 & 74.8 & 14.5 & 42 & 54 & 46.7 & 3.7 \\
\hline & 2 & 54 & 95 & 74.8 & 16.5 & 44 & 55 & 48 & 3.5 \\
\hline & 4 & 53 & 98 & 76 & 15.9 & 45 & 56 & 49.5 & 3.3 \\
\hline & 5 & 55 & 90 & 72.5 & 13.6 & 45 & 57 & 50.1 & 3.7 \\
\hline \multirow[t]{3}{*}{2} & 3 & 74 & 124 & 100.2 & 18.1 & 43 & 70 & 50.5 & 8.4 \\
\hline & 1 & 55 & 87 & 72 & 13 & 45 & 72 & 52.8 & 8.2 \\
\hline & 2 & 63 & 107 & 78.4 & 16.8 & 46 & 74 & 54.1 & 8.5 \\
\hline
\end{tabular}

Table 2 Overview of transport lead times in pre-cooperation and cooperative periods (hours) 
Table 2 Overview of transport lead times in pre-cooperation and cooperative periods (hours) (continued)

\begin{tabular}{|c|c|c|c|c|c|c|c|c|c|}
\hline \multirow{2}{*}{ Coalition } & \multirow{2}{*}{ Firm } & \multicolumn{3}{|c|}{ Before collaboration } & \multirow{2}{*}{$S D$} & \multicolumn{3}{|c|}{ After collaboration } & \multirow{2}{*}{$S D$} \\
\hline & & Min & $\operatorname{Max}$ & Mean & & Min & $\operatorname{Max}$ & Mean & \\
\hline \multirow[t]{4}{*}{3} & 1 & 28 & 84 & 54.7 & 21.3 & 26 & 51 & 39 & 9.8 \\
\hline & 2 & 31 & 55 & 47.8 & 16.5 & 27 & 52 & 39.2 & 10.2 \\
\hline & 4 & 36 & 71 & 58.2 & 12.1 & 29 & 53 & 40.7 & 10.1 \\
\hline & 5 & 38 & 57 & 49.5 & 9 & 30 & 54 & 41.8 & 9.9 \\
\hline
\end{tabular}

From the above table it can be observed that the mean lead time has been reduced. This is confirmed by the result for the Mann-Whitney U-test in Table 3:

Table 3 Mann-Whitney U test for lead time duration

\begin{tabular}{ccccc}
\hline Coalition & Firm & $Z$ & $p$-value & Result \\
\hline 1 & 1 & -3.125 & .0005 & $\mathrm{H}_{0}$ rejected \\
& 2 & -3.130 & .0005 & $\mathrm{H}_{0}$ rejected \\
& 4 & -3.130 & .0005 & $\mathrm{H}_{0}$ rejected \\
& 5 & -3.139 & .001 & $\mathrm{H}_{0}$ rejected \\
2 & 1 & -2.898 & .001 & $\mathrm{H}_{0}$ rejected \\
& 2 & -2.898 & .001 & $\mathrm{H}_{0}$ rejected \\
& 3 & -3.243 & .000 & $\mathrm{H}_{0}$ rejected \\
3 & 1 & -1.511 & .076 & $\mathrm{H}_{0}$ supported \\
& 2 & -2.435 & .007 & $\mathrm{H}_{0}$ rejected \\
& 4 & -1.680 & .047 & $\mathrm{H}_{0}$ rejected \\
& 5 & -1.333 & .094 & $\mathrm{H}_{0}$ supported \\
\hline
\end{tabular}

Null hypothesis is rejected for all cooperators in first and second coalitions. However, this hypothesis was only rejected for Firm 2 and Firm4 in the third coalition. Although a lead time reduction is apparent for all firms in this coalition, they are not statistically meaningful at the 5\% significance level for Firm1 and Firm5.

This indicates that horizontal cooperation in transport could reduce the duration of transportation lead time. By considering all coalition, the lead-time duration has been reduced on average of $30.79 \%$ in this empirical case. Figure 3 illustrates the marginal changes of means in three coalitions.

The percentage of lead-time reduction or synergy achieved is influenced by the mean lead time before collaboration, the geographical location of the firm in the joint route plan and the order of deliveries in the joint route distribution. In this research we have not separately investigated the different components of transportation lead-time as the linehaul component and consolidation time. Since the mode of transportation has not been changed in the cooperative distribution scenario, the average speed of the line-haul component remained unchanged. However, there are two other causes that result the time reductions. First, the shorter travelling times which were achieved by means of direct routes from the supplier to shippers. Second, avoiding the transshipment process eliminated the unnecessary storage and waiting times in the consolidation centres. The time savings heavily depend on the coordination level between different parties such as 
supplier, transport service providers and shipper in the cooperative network. For example, removing the line-haul component of the service from supplier to the shipper's region, knowing the arrival times enables the shipper to prepare for unloading and consequently reducing the time a vehicle is spending there. Table 4 shows the percentage of reduction for coalitions and related shippers.

Figure 3 Changes in average of lead times before and after collaboration (see online version for colours)

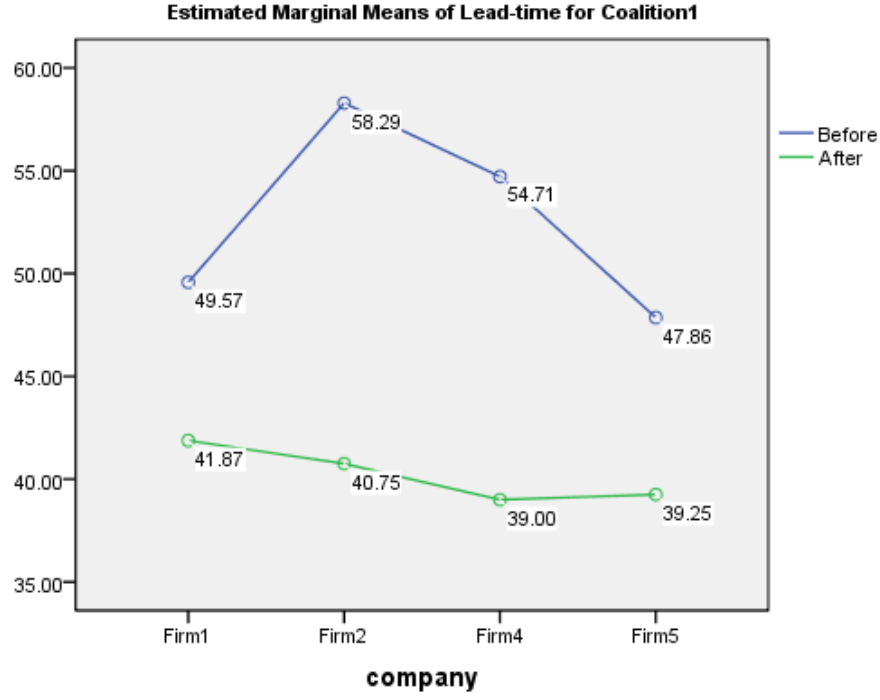

(a)

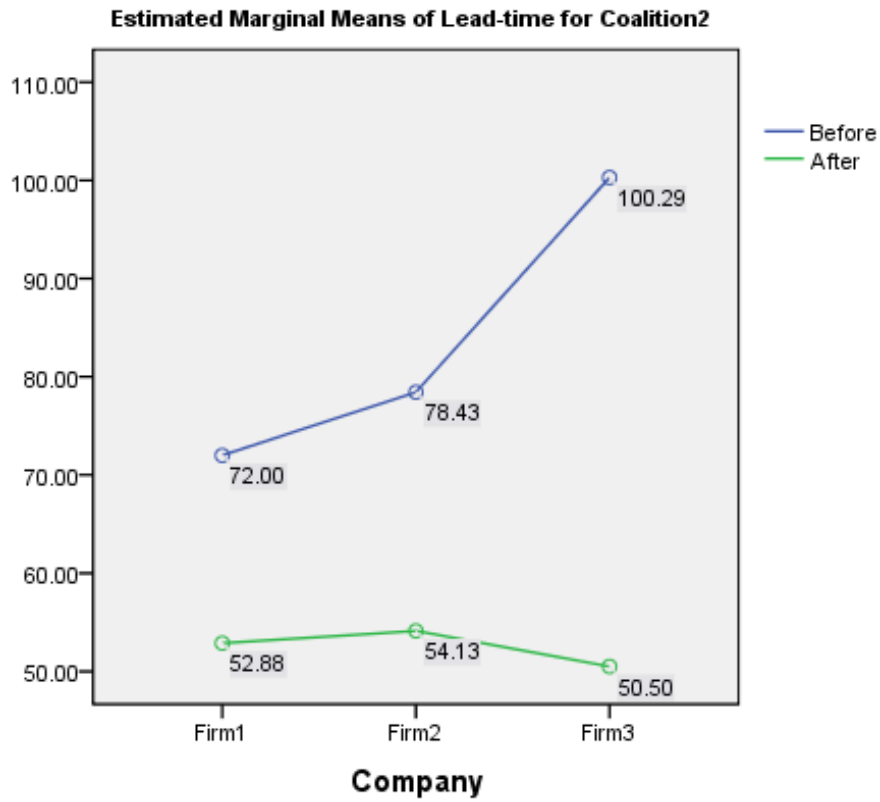

(b) 
Figure 3 Changes in average of lead times before and after collaboration (continued) (see online version for colours)

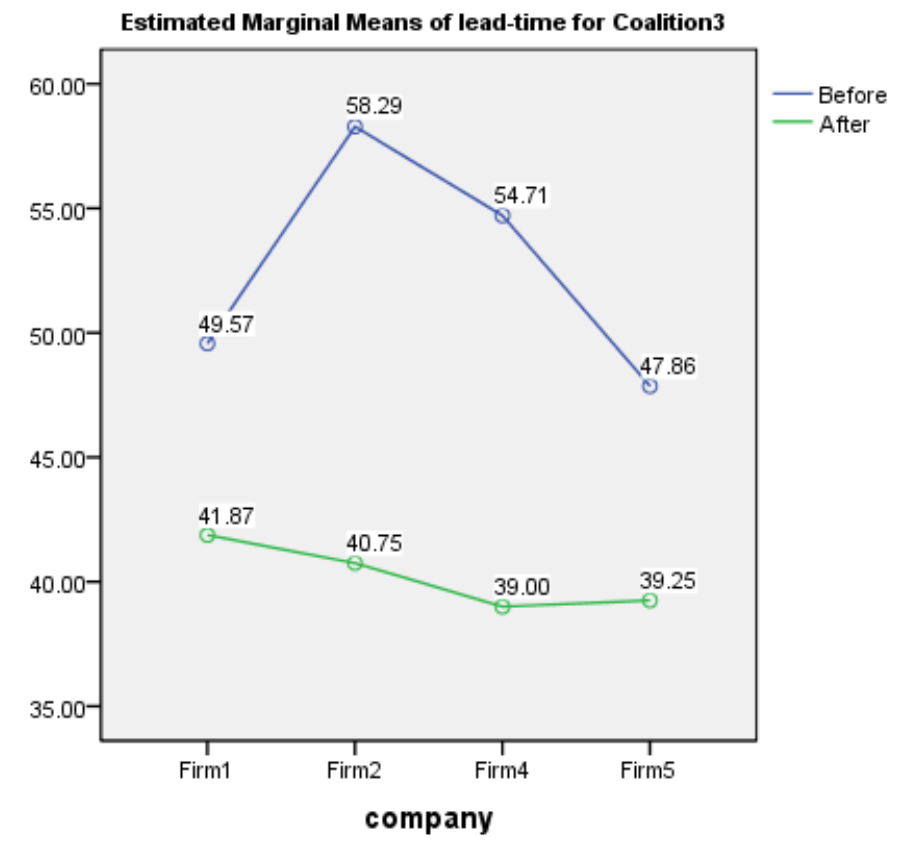

(c)

Table 4 Overview of changes in the mean lead time

\begin{tabular}{lccc}
\hline Coalition & Firm & \% of reduction for firm & \% of reduction for coalition \\
\hline 1 & 1 & 37.56 & 34.79 \\
& 2 & 35.82 & \\
& 4 & 34.86 & \\
2 & 5 & 30.89 & 35.75 \\
& 1 & 49.6 & \\
& 2 & 26.66 & \\
3 & 3 & 30.99 & \\
& 1 & 28.70 & \\
& 2 & 17.99 & \\
& 4 & 30.06 & \\
& 5 & 15.55 & \\
\hline
\end{tabular}

It is a well-known fact that the pressure to reduce the cost of inventories in supply chains has increased. One way to reduce the inventory cost without lowering the service level is to better manage the lead times and the variability of lead times. Investigating the impact of cooperative transport on the variability of lead times is the second objective of this research. For this purpose, we used the CV to analyse the impact of cooperation on the variability for both time periods. The population under investigation of lead-time variability analysis consists of three coalitions. The results support reduction in two 
coalitions as well as two firms from the third coalition. This indicates that lead-time variability has been reduced in cooperative transport in 9 cases out of 11 .

To examine the variances of lead-times for before and after cooperation, we have employed the average CV for each firm and Bartlett's test for homogeneity of variances (under a significance level of 5\%). The results are presented in Table 5:

Table 5 Overview of changes in variances based on CV and the results of Bartlett's test

\begin{tabular}{ccccccc}
\hline Coalition & Firm & CV before & CV after & Change\% & $p$-value & Result \\
\hline 1 & 1 & 19.41 & 8.06 & 58.4 & 0.003 & Unequal \\
& 2 & 22.06 & 7.38 & 66.5 & 0.000 & Unequal \\
& 4 & 21.01 & 6.74 & 67.9 & 0.000 & Unequal \\
& 5 & 18.73 & 7.34 & 60.8 & 0.003 & Unequal \\
& 1 & 18.12 & 16.63 & 8.2 & 0.044 & Unequal \\
& 2 & 18.12 & 15.64 & 13.7 & 0.240 & Equal \\
& 3 & 21.42 & 15.78 & 26.3 & 0.049 & Unequal \\
3 & 1 & 39.05 & 25.34 & 35 & 0.047 & Unequal \\
& 2 & 34.66 & 25.97 & 25 & 0.091 & Equal \\
& 4 & 20.84 & 24.70 & -18.5 & 0.340 & Equal \\
& 5 & 18.29 & 23.65 & -29.2 & 0.820 & Equal \\
\hline
\end{tabular}

The results from Bartlett's test demonstrates homogeneity of variances for all the firms in Coalition 1, two firms out of three from Coalition 2 and one firm out of four from the third coalition.

\section{Concluding remarks}

Highly responsive networks such as fast-moving consumer goods (FMCG) and the automotive industry illustrate the pressure to better manage inventories. One way to reduce the inventory cost without lowering the service level is to have a better control over variability of lead time.

This research aims at examining the lead time elements and potential reductions of cooperation for shippers and LSPs. This study offers the first empirical analysis on lead time management in horizontal cooperation in logistics and transport and provides a new direction for LSPs and industrial firms struggling with managing their transportation lead times. Cooperation in transport could eventually lead to reduced lead times and lower variability of lead time which is in general beneficial for reducing inventory costs (Dullaert and Zamparini, 2013).

We surveyed the literature on lead-time management and examined how cooperation can affect the lead times of the participating companies for a particular case in the food industry. We showed that transportation lead time can be reduced by consolidating the orders which avoids transshipments and multi-drop routes. However, this approach is suitable when there is not a direct route or in case of infrequent service between supplier and shipper. Geographical proximity and availability of transportation service between supplier and shippers plays a crucial role in design and establishment of cooperation. In a 
larger geographical zone with less direct routes available, larger economies of scale (Ghaderi et al., 2012) and more lead time reductions are possible.

Further research will be aimed at developing a decision-making framework for management of lead time in generic cooperative transport networks by seeing the coordination costs to control lead time and lead time variability.

\section{Acknowledgements}

The authors would like to thank the anonymous reviewers for their valuable comments and suggestions to improve the presentation of this manuscript.

\section{References}

Audy, J.F., D'Amours, S. and Rousseau, L.M. (2011) 'Cost allocation in the establishment of a collaborative transportation agreement: an application in the furniture industry', Journal of the Operational Research Society, Vol. 62, No. 6, pp.960-970.

Barratt, M. (2004) 'Understanding the meaning of collaboration in supply chain', Supply Chain Management: An International Journal, Vol. 9, No. 1, pp.30-42.

Benacchio, M., Ferrarib, C. and Musso, E. (2007) 'The liner shipping industry and EU competition rules', Transport Policy, Vol. 14, No. 1, pp.1-10.

Cruijssen, F. (2006) Horizontal Cooperation in Transport and Logistics, PhD Thesis, University of Tilburg, Netherlands.

Cruijssen, F. and Salomon, M. (2004) Empirical Study: Order Sharing Between Transportation Companies May Result in Cost Reductions Between 5 to 15 Percent, CentER Discussion Paper 2004-80, Tilburg University, Netherlands.

Cruijssen, F., Cools, M. and Dullaert, W. (2007a) 'Horizontal cooperation in logistics: opportunities and impediments', Transportation Research: Part E, Vol. 43, No. 2, pp.129-142.

Cruijssen, F., Dullaert, W. and Fleuren, H. (2007b) 'Horizontal cooperation in transport and logistics: a literature review’, Transportation Journal, Vol. 46, No. 3, pp.22-39.

Cruijssen, F., Bräysy, O., Dullaert, W., Fleuren, H. and Salomon, M. (2007c) 'Joint rout planning under varying market conditions', International Journal of Physical Distribution \& Logistics Management, Vol. 37, No. 4, pp.287-304.

Dullaert, W. and Zamparini, L. (2013) 'The impact of lead time reliability in freight transport: a logistics assessment of transport economics findings', Transportation Research Part E. Logistics and Transportation Review, Vol.49, No. 1, pp.190-200.

Fan, T., Vigeant-Langlois, L., Geissler, C., Bosler, B. and Wilmking, J. (2001) 'Evolution of global airline strategic alliance and consolidation in the twenty-first century', Journal of Air Transport Management, Vol. 7, No. 6, pp.349-360.

Fransoo, J.C. and Wouters, M.J.F. (2000) 'Measuring the bullwhip effect in the supply chain', Supply Chain Management: An International Journal, Vol. 5, No. 2, pp.78-89.

Frisk, M., Göthe-Lundgren, M., Jörnsten, K. and Rönnqvist, M. (2010) 'Cost allocation in collaborative forest transportation', European Journal of Operational Research, Vol. 205, No. 2, pp.448-458.

Ghaderi, H. and Dullaert, W. (2012) 'An empirical investigation of lead-time reduction in purchasing groups: evidence from SMEs', International Journal of Logistics Systems and Management, Vol. 13, No. 3, pp.379-392. 
Ghaderi, H., Darestani, S.A., Leman, Z. and Ismail, M.Y. (2012) 'Horizontal collaboration in logistics: a feasible task for group purchasing', International Journal of Procurement, Vol. 5, No. 1, pp.43-54.

Hendrick, T.E. (1997) Purchasing Consortiums: Horizontal Alliances Among Firms Buying Common Goods and Services: What? Who? Why? How, Center for Advanced Purchasing Studies, Tempe.

Hingley, M., Lindgreen, A., Grant, D.V. and Kane, C. (2011) 'Using fourth-party logistics management to improve horizontal collaboration among grocery retailers', Supply Chain Management: An International Journal, Vol. 16, No. 5, pp.316-327.

Hoang, H. and Rothaermel, F. (2005) 'The effect of general and partner-specific alliance experience on joint R\&D project performance', Academy of Management Journal, Vol. 48, No. 2, pp.332-345.

Jayaram, J., Vickery, S.K. and Droge, C. (1999) 'An empirical study of time based competition in the North American automotive supplier industry', International Journal of Operations and Production Management, Vol. 19, No. 10, pp.1010-1033.

Kale, P., Dyer, J.H. and Singh, H. (2002) 'Alliance capability, stock market response, and long-term alliance success: the role of the alliance function', Strategic Management Journal, Vol. 23, No. 8, pp.747-767.

Krajewska, M.A., Kopfer, H., Laporte, G., Ropke, S. and Zaccour, G. (2008) 'Horizontal cooperation among freight carriers: request allocation and profit sharing', Journal of the Operational Research Society, Vol. 59, No. 11, pp.1483-1491.

Leitner, R., Meizer, F., Prochazka, M. and Sihn, W. (2011) 'Structural concepts for horizontal cooperation to increase efficiency in logistics', CIRP Journal of Manufacturing Science and Technology, Vol. 4, No. 3, pp.332-337.

Leng, M. and Parlar, M. (2009) 'Lead-time reduction in a two-level supply chain: non-cooperative equilibria vs. coordination with a profit-sharing contract', International Journal of Production Economics, Vol. 118, No. 2, pp.521-544.

Liou, J.J.H. (2012) 'Developing an integrated model for the selection of strategic alliance partners in the airline industry', Knowledge-based Systems, Vol. 28, pp.59-67.

Mason, R., Lalwani, C. and Boughton, R. (2007) 'Combining vertical and horizontal collaboration for transport optimization', Supply Chain Management: An International Journal, Vol. 12, No. 3, pp.187-199.

Oum, T., Park, J-H., Kim, K. and Yu, C. (2002) 'The effect of horizontal alliances on firm productivity and profitability: evidence from the global airline industry', Journal of Business Research, Vol. 57, No. 8, pp.844-853.

Ozener, O. and Ergun, O. (2008) 'Allocating costs in a collaborative transportation procurement network’, Transportation Science, Vol. 42, No. 2, pp.146-165.

Panayides, P.M. and Wiedmer, R. (2011) 'Strategic alliances in container liner shipping', Research in Transportation Economics, Vol. 32, No. 1, pp.25-38.

Park, S.H. and Ungson, G.R. (2001) 'Interfirm rivalry and managerial complexity: a conceptual framework of alliance failure', Organization Science, Vol. 12, No. 1, pp.37-53.

Rhoades, D.L. and Lush, H. (1997) 'A typology of strategic alliances in the airline industry: propositions for stability and duration', Journal of Air Transport Management, Vol. 3, No. 3, pp.109-114.

Schmoltzi, C. and Wallenburg, C.M. (2010) 'Horizontal cooperations between logistics service providers: motives, structure, performance', International Journal of Physical Distribution \& Logistics Management, Vol. 41, No. 6, pp.552-576.

Shepperd, E. and Seidman, D. (2001) 'Ocean shipping alliances: the wave of the future', International Journal of Maritime Economics, Vol. 3, No. 4, pp.351-367.

Simchi-Levi, D., Kaminsky, P. and Simchi-Levi, E. (1999) Designing and Managing the Supply Chain: Concepts, Strategies and Cases, McGraw-Hill, Irwin. 
Tersine, R.J. and Hummingbird, E.A. (1995) 'Lead-time reduction: the search for competitive advantage', International Journal of Operations and Production Management, Vol. 15, No. 2, pp.8-18.

Verstrepen, S., Cools, M., Cruijssen, F. and Dullaert, W. (2009) 'A dynamic framework for managing horizontal cooperation in logistics', International. Journal of Logistics Systems and Management, Vol. 5, Nos. 3/4, pp.228-248.

Wallenburg, C.M. and Raue, J.S. (2011) 'Conflict and its governance in horizontal cooperations of logistics service providers', International Journal of Physical Distribution \& Logistics Management, Vol. 41, No. 4, pp.385-400.

Wedel, L. and Lumsden, K. (1995) 'The influence of lead time reduction on decisions and rules in the production planning process', International Journal of Production Economics, Vol. 41, Nos. 1-3, pp.399-404.

Yilmaz, O. and Savasaneril, S. (2010) 'Collaboration among small shippers in a transportation market', European Journal of Operational Research, Vol. 218, No. 2, pp.408-415. 